\section{Improving the clarity and consistency of advice on missed contraceptive pills in the UK}

We write to report the findings of a questionnaire study within a large family planning centre in the UK that examined women's knowledge and understanding of the current missed pills rules. Three different sets of missed pill rules have been available to the 3.5 million combined oral contraception (COC) users in the UK. The guidance from the World Health Organization and the Faculty of Sexual and Reproductive Healthcare (FSRH) reflected the current scientific, evidence-based recommendations. ${ }^{1}$ This evidence-based guidance was not reflected in UK National Licences [in patient information leaflets (PIL)] or, in full, by the British National Formulary.

A total of $117 \mathrm{COC}$ users completed a questionnaire evaluating their frequency of missed pills, knowledge of their current preparation, sources of information following missed pills and what action they would take following missed pills in three scenarios.

Missed pills were very common and nearly three quarters of women reported missing pills in the preceding 3 months (95\% CI 0.650-0.821). The PIL was the most frequent source of advice regarding missed pills (used by $62.6 \%$ of women) followed by friends (12\%) and then the family planning clinic (7\%). Only $17.6 \%$ of women knew the dose of estrogen in their pill preparation (20 or $30 \mu \mathrm{g}$ ) although $88 \%$ knew the brand name.

Within the scenarios, only $11.8 \%$ and $6.9 \%$ correctly followed the evidencebased guidelines after two missed pills in the first and second weeks, respectively. No women adhered to the evidence-based guidelines after missing three pills during the third week of their cycle. Following missed pills, only half of women knew the correct pill to take.

We conclude that women appear to miss pills frequently but appear unsure of the correct action to take. The evidencebased missed pill rules were complicated to follow and different advice was contained within the pill information leaflets, which was confusing. Perhaps "one rule for all estrogen dosages" would be better, resembling the guidance from the American College of Obstetricians and Gynecologists, which recommends that if more than one pill is missed, back up contraception should be used for 1 week regardless of the pill dose or timing in the cycle. ${ }^{2}$ Similarly, The Netherlands had four separate recommendations on missed pills until 2007. Their current national guideline concludes that if one pill is missed, no extra precautions were necessary, but if two or more pills were missed, advice would be given in accordance with existing evidence based guidelines for $20 \mu \mathrm{g}$ pills. ${ }^{3}$

On the basis of this study, we concluded that clarification and simplification of the rules in the UK was similarly required to improve their clinical value and that all sources of information in the UK should contain consistent advice. It is therefore pleasing that the Medicines and Healthcare products Regulatory Authority, FSRH and Family Planning Association have worked together in recent months to harmonise and simplify the advice in the UK, and that these new recommendations will now be put in place with immediate effect. ${ }^{45}$

\section{Elizabeth Greed}

Medical Student, University of Edinburgh, Edinburgh, UK; e.m.greed@sms.ed.ac.uk

Ailsa Gebbie, FRCOG, FFSRH

Director of Family Planning, NHS Lothian, Edinburgh, UK; ailsa.gebbie@nhslothian.scot.nhs.uk

\section{Competing interests None.}

J Fam Plann Reprod Health Care 2011;37:187. doi:10.1136/fprhc-2011-0139

\section{REFERENCES}

1 Faculty of Family Planning and Reproductive Healthcare Clinical Effectiveness Unit. Faculty Statement from the CEU on New Publication: WHO Selected Practice Recommendations Update Missed Pills: New Recommendations. 2005. http://www.ffprhc.org.uk/admin/uploads/ MissedPillRules\%20.pdf [accessed 5 May 2011]

2 American College of Obstetricians and Gynecologists. Birth Control Pills (Patient Education Pamphlet AP021). 2011. http://www. acog.org/publications/patient_education/bp021. cfm [accessed 5 May 2011].

3 Boukes FS, Wiersma TJ, de Leest K, et al. New recommendations as regards forgetting to take the contraceptive pill [in Dutch]. Ned Tijdschr Geneeskd 2007:151:1923-1926.

4 Medicines and Healthcare products Regulatory Authority (MHRA). MHRA UK Public Assessment Report. Combined Oral Contraceptives (The Pill): When to Start Taking The Pill, and Missed Pill Advice. 2011. http://www.mhra.gov.uk/Safetyinformation/ Generalsafetyinformationandadvice/ Product-specificinformationandadvice/ Product-specificinformationandadvice-G-L/ Hormonalcontraceptives/index.htm [accessed 13 May 2011].

5 Faculty of Sexual and Reproductive Healthcare Clinical Effectiveness Unit. CEU Statement (May 2011): Missed Pill Recommendations. 2011. http://www.fsrh.org/ admin/uploads/StatementCEUMissedPills.pdf [accessed 13 May 2011]. 